\title{
Effect of Air Gap Distance on PES/PVA Hollow Fibre Membrane's Morphology and Performance
}

\author{
Abdul Latif Ahmad* and Zulfida Mohamad Hafis Mohd Shafie \\ School of Chemical Engineering, Universiti Sains Malaysia, \\ Engineering Campus, 14300 Nibong Tebal, Penang, Malaysia \\ *Corresponding author: chlatif@usm.my
}

Published online: 15 February 2017

To cite this article: Ahmad, A. L. \& Mohd Shafie, Z. M. H. (2017). Effect of air gap distance on PES/PVA hollow fibre membrane's morphology and performance. J. Phys. Sci., 28(Supp. 1), 185-199, https://doi.org/10.21315/jps2017.28.s1.12

To link to this article: https://doi.org/10.21315/jps2017.28.s1.12

\begin{abstract}
New formulation of polyether sulfone (PES)/polyvinyl alcohol (PVA) hollow fibre (HF) membranes were spun at different air gap distances to study the effect on membrane's morphology and performance. Four different air gap distances (5, 10, 15 and $20 \mathrm{~cm}$ ) were investigated. The results suggested that air gap played a significant role in determining the circularity of inner lumen and the dimension of the fibres, with oval lumen formed at low air gap of $5 \mathrm{~cm}$ and became circular at higher air gap distance. Membrane dimensions were reduced with increasing air gap distance, with the outer diameter shrank from $0.881 \pm 0.004 \mathrm{~mm}$ at $5 \mathrm{~cm}$ air gap down to $0.724 \pm 0.008 \mathrm{~mm}$ at $20 \mathrm{~cm}$ air gap, and inner lumen diameter shrank from $0.564 \pm 0.003 \mathrm{~mm}$ at $5 \mathrm{~cm}$ air gap down to $0.464 \pm 0.005$ $\mathrm{mm}$ at $20 \mathrm{~cm}$ air gap. On top of that, the flux and foulant rejection could be altered when using similarly formulated membrane spun at different air gap distance. After 30 min of hydraulic compaction and $1 \mathrm{~h}$ of deionised water permeation, maximum water flux was noted at $42.32 \pm 0.12 \mathrm{~kg} / \mathrm{m}^{2} . h$ for HF spun at the air gap of $15 \mathrm{~cm}$. Similar trend was noted after another $1 \mathrm{~h}$ of humic acid permeation as model foulant, with maximum flux found at $42.86 \pm 0.09 \mathrm{~kg} / \mathrm{m}^{2} . h$ for the same membrane sample at $15 \mathrm{~cm}$ air gap. Nevertheless, rejection was found to be the highest for HF spun at $5 \mathrm{~cm}$ air gap with $94.63 \pm 2.13 \%$ humic acid rejection.
\end{abstract}

Keywords: Hollow fibre membrane, air gap distance, humic acid rejection, polyether sulfone, polyvinyl alcohol 


\section{INTRODUCTION}

Large surface area to volume ratio, higher productivity per unit volume, mechanically self-supporting, and high recovery tolerance in individual membrane units; these are some of the advantages usually associated with hollow fibre (HF) membranes, making it the favoured geometry for most membrane separation applications. ${ }^{1,2}$ Nevertheless, fabrication of HF membranes has been noted to be troublesome as compared to its flat sheet counterpart, particularly due to the increase in number of parameters that need to be considered. Among all of the spinning parameters noted for dry-jet wet-spinning HF membrane process, air gap distance has been the interest of many researchers..$^{3-9}$ Despite its similarity to the dry phase inversion during flat sheet membrane fabrication, HF membranes undergo the dry phase inversion in vertical with bore fluid flowing in the lumen. The configuration differences induce an additional stress to the membrane's structure due to gravity. On top of that, the internal surface also starts to develop immediately after extrusion from the spinneret as it is in contact with the bore fluid. ${ }^{3}$

The length of air gap (or air gap residence time) in HF membrane fabrication has been noted by other researchers to be an important factor in altering the outer skin layer. ${ }^{5}$ Notwithstanding, the observations of air gap effect on HF membrane morphology and permeation were rather conflicting especially between membranes with different formulations. For example, dimension, morphology and separation performance of polyvinylidene fluoride (PVDF) HF membranes have been reported by Khayet, where wall thickness of the fibres shrunk with increasing air gaps. Nevertheless, the inner diameter remained almost constant at air gap of $5 \mathrm{~cm}$ to $80 \mathrm{~cm}$. Permeation on the other hand, decreased with higher air gap, but increased in terms of solute separation performance signifying denser cross section and smaller pore size. ${ }^{3}$ Another work by Khayet et al. using polyvinyl chloride (PVC) HF membranes reported decreasing internal and external diameter with increasing air gap, while permeation increased and selectivity decreased with increasing air gap, contradicting to his earlier work with PVDF. ${ }^{4}$ Polyether sulfone (PES) HF membranes have been reported by Liu et al. to develop larger pores when air gap increases. This in turn increased the water flux but lowered the foulant bovine serum albumin (BSA) rejection. ${ }^{5}$ Chwojnowski et. al. on the other hand reported the effect of humidity on the membrane skin layer during the air gap region. Low humidity below $90 \%$ induced a thinner skin layer which created longitudinal cracks along the membrane's outer surface. ${ }^{6}$ Nevertheless, this effect which emerged at quite a high humidity limit has not been seen in other works mentioned earlier, nor do the works mentioned about the testing humidity conditions, suggesting that dope formulation played a role in the deformity. The work of Peng et al. introduced the concept of acceleration of stretch and critical air 
gap distance in fabricating macrovoid-free hollow fibres. In this study, it was noted that the number of macrovoids per unit area decreased with longer air gap distance, and completely disappeared when it reached a critical value. ${ }^{7}$ However, it should also be noted that the critical value still depends on the type of polymer, polymer concentration and take-up speed. Plus, no effect on permeability and rejection was concluded by the studies conducted by the authors.

On the other hand, the use of polyvinyl alcohol (PVA) as pore former or additive has been quite sporadic as compared to other hydrophilic polymers such as polyethylene glycol (PEG) and polyvinyl pyrollidone (PVP). Despite of its abundant of $-\mathrm{OH}$ functional groups, a fully hydrolysed PVA is hard to dissolve and is insoluble in polar organic solvent due to extreme inter and intra molecular hydrogen bonding between its abundant hydroxyl groups. ${ }^{10}$ This may have caused the lack of popularity for PVA blends research. Chetri et al. have noted that without a suitable catalyst, PVA is basically non soluble in organic solvent such as dimethylacetamide (DMAc), and only slightly soluble in dimethyl formamide (DMF) and dimethyl sulfoxide (DMSO) at minimum temperature of $50^{\circ} \mathrm{C} .1^{10}$ Nevertheless, lithium chloride $(\mathrm{LiCl})$ has been noted to be able to solubilise PVA in DMAc solvent, with maximum solubility as high as $6.7 \mathrm{w} / \mathrm{v} \%$ at $40^{\circ} \mathrm{C}$ as compared to DMSO which only exhibits swelling at the same temperature. ${ }^{11}$ The incorporation of $\mathrm{LiCl}$ may induce an added benefit to the membrane's permeation as $\mathrm{LiCl}$ is also known to be a good pore former for membrane fabrication. ${ }^{12,13}$

Based on the various reports collected, no definite conclusion could be made on the effect of air gaps on HF membrane morphology and performance spun with different formulations. On top of this, no PVA blended HF membranes have been accounted by the authors, or at least PES/PVA blends in HF configuration so far. Hence, the effect of air gap distance on the membrane structures of PES/PVA HF membranes remains a question to be studied.

\section{EXPERIMENTAL}

\subsection{Materials}

PES (Ultrason E6020P, BASF) was used as the base material of the hollow fibre (HF) membrane. It was oven dried prior to usage to remove any moisture contents. PVA (fully hydrolysed, MW: 15,000, Merck) was used as pore former and hydrophilic additive. N,N-dimethylacetamide, DMAc (anhydrous 99.8\%, Sigma Aldrich) was used as the solvent for the dope solution. Lithium chloride, $\mathrm{LiCl}$ (ACS Reag. Ph Eur., Merck) was used to improve PVA homogeneity in DMAc. 
Other materials include glycerol ( $>99.5 \%$, Sigma Aldrich) and ethanol (EMSURE ACS, ISO, Reag. Ph Eur., Merck) which were used in post treatment, Araldite epoxy (rapid 5 min and standard $90 \mathrm{~min}$ ) for module preparation, and humic acid (technical grade, Sigma Aldrich) as model foulant for rejection studies.

\subsection{Membrane Fabrication and Module Preparation}

$\mathrm{PES} / \mathrm{DMAc} / \mathrm{PVA}$ were maintained at weight ratio of $17.5 / 79.5 / 1$ while $\mathrm{LiCl}$ was added equimolar to the amount of PVA added. $\mathrm{LiCl}$ was premixed in DMAc using magnetic stirrer for $30 \mathrm{~min}$ at $60^{\circ} \mathrm{C}, 500 \mathrm{RPM}$. PVA was then added into the mixture and mixed for another $3 \mathrm{~h}$. Dried PES flakes were then added and mixed for $18 \mathrm{~h}$ at $60^{\circ} \mathrm{C}, 700 \mathrm{RPM}$ using mechanical stirrer. Once fully mixed, the dope solutions were placed in ultrasonicator bath for degassing purpose, for another $1 \mathrm{~h}$. The solutions were then ready to be used for HF membrane spinning.

The synthesised dope solutions were spun at four different air gaps as noted in Table 1. Spinning was done through dry jet wet spinning method. The take-up drum speed was adjusted manually to maintain a minimum speed where the fibres were not artificially stretched (only stretched gravitationally) but yet did not accumulate in the coagulation bath. All other parameters were fixed throughout the spinning process. Filtered water and distilled water were used as both coagulation bath and bore fluid respectively. Spun membranes were then immersed in water for two days to completely remove any traces of solvent. The membranes were then immersed in $50 \mathrm{v} / \mathrm{v} \%$ of glycerol/water mixture for 1 day and dried under ambient conditions to preserve the membrane's pore structures. Prior to flux testing, the membranes were prepared into modules with 4 strands per module, and immersed in ethanol for $6 \mathrm{~h}$ to remove the glycerol and kept in cold water until further usage.

\subsection{Membrane Morphology}

The HF membrane's surface and cross sectional morphology were observed under scanning electron microscope, SEM (Hitachi TM 3000 Tabletop). Prior to the characterisation, the membrane samples were coated with thin layer of gold/palladium using sputter coater (Quorum SC7620) for $90 \mathrm{~s}$. As for the cross sectional morphology, membranes were first cracked by using liquid nitrogen in order to get a clean cut of the membranes. The diameters of the membranes (internal and external) were noted using ImageJ software. 
Table 1: Air gap distance and minimum take-up drum speed needed to avoid membrane agglomeration for the fabricated HF membranes.

\begin{tabular}{ccc}
\hline Membrane samples & Air gap $(\mathrm{cm})$ & Take-up speed (RPM) \\
\hline A.1 & 5 & 6.576 \\
A.2 & 10 & 7.578 \\
A.3 & 15 & 8.580 \\
A.4 & 20 & 9.582 \\
\hline
\end{tabular}

\subsection{Flux and Rejection Performance}

Prior to flux performance test, the prepared membrane modules were subjected to hydraulic compression at 2 bar for $30 \mathrm{~min}$, using deionised water as the feed. The membrane modules were then tested for water flux at 1.5 bar for $1 \mathrm{~h}$. The flux was calculated according to the following equation:

$$
J=\Delta m /\left(4 \times C_{o} \times L_{e} \times \Delta t\right)
$$

where $J\left(\mathrm{~kg} \mathrm{~m}^{-2} \mathrm{~h}^{-1}\right)$ is the flux, $\Delta m(\mathrm{~kg})$ is the mass of permeate, $C_{o}(\mathrm{~m})$ the average outer circumference of the membrane, $L_{e}(\mathrm{~m})$ the effective length of the membrane strands and $\Delta t(\mathrm{~h})$ the permeation time. All flux testing were conducted at constant feed flowrate of $600 \mathrm{ml} / \mathrm{min}$. To determine the rejection performance, feed solution of $20 \mathrm{mg} / \mathrm{L}$ humic acid in deionised water (adjusted to $\mathrm{pH} 7.4$ using $0.1 \mathrm{M} \mathrm{NaOH}$ solution) were introduced for another $1 \mathrm{~h}$ at the same pressure and flowrate. The sample of the permeate was taken for HA rejection determination using UV-vis spectrometer (Merck Spectroquant Pharo 300) at the wavelength of $254 \mathrm{~nm}$. The rejections were calculated by:

$$
R=\left(1-C_{p} / C_{f}\right) \times 100
$$

where $R(\%)$ is the HA rejection, $C_{p}(\mathrm{mg} / \mathrm{L})$ the HA concentration of the permeate and $C_{f}(\mathrm{mg} / \mathrm{L})$ the HA concentration of the feed.

\subsection{Feasibility Studies}

The feasibility of the HF membranes was calculated using normalised convex combination of the responding variable:

$$
\text { Feasibility }=\left(\sum_{i}^{\infty} w_{i} f_{i}\right) \times 100
$$


where $f$ represents the response's normalised value, which can be calculated by dividing the sample's response of interest value with the highest response value in the overall population. In this experiment, response refers to responding variable such as flux and rejection. $w$ represents the weightage of the response's importance as compared to the other responses in the population, which should sum up to 1, while subscript $i$ refers to every response considered in the study.

\section{RESULTS AND DISCUSSION}

\subsection{Surface Morphology}

Figure 1 presents the SEM micrograph image for the surface at $\times 3000$ magnification. All of the surfaces exhibit similar collinear pores along the length of the membranes, suggesting that the morphology was possibly due to gravitational stretching of the membranes. This was further suggested by comparing the micrograph with the work of others on PES/PVA flat sheet membranes which did not develop the same morphology. ${ }^{14-16}$ Interestingly, the collinear pores also did not immerge in other
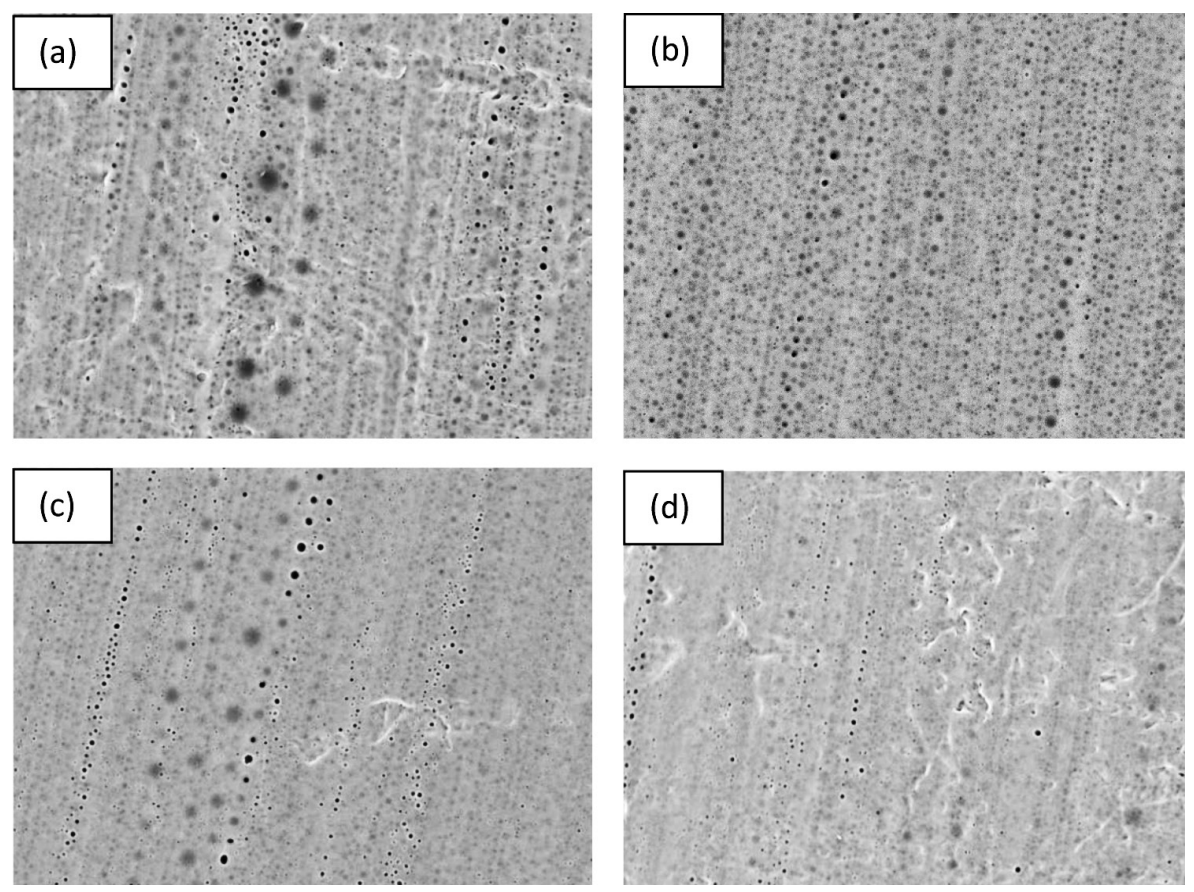

Figure 1: SEM surface micrograph $(\times 3000$ magnification $)$ of HF membrane samples spun at (a) $5 \mathrm{~cm}$, (b) $10 \mathrm{~cm}$, (c) $15 \mathrm{~cm}$, and (d) $20 \mathrm{~cm}$ respectively. 
HF membranes works. ${ }^{5,17-19}$ One hypothesis is that the gravitational stretching or the flow induced shear stress inside the spinneret affects the PVA's polymer chain orientation during the air gap region. The strong interaction between PVA's hydroxyl groups creates a linkage between the polymer chains. Once the dope solution reached the coagulation bath, the PVA then underwent phase inversion while maintaining the chain orientation due to the linkage mentioned earlier. As a result, distinct collinear pore pattern were formed.

\subsection{Cross Sectional Morphology}

The cross sectional micrograph at $\times 150$ magnification presented in Figure 2 shows that non-circular lumen were formed at air gap of $5 \mathrm{~cm}$ (sample A.1), while circular lumen were produced at other air gaps. The short air gap introduced in sample A.1 does not give the fibre enough relaxation time to reduce the effect of die swelling. With the use of water as bore fluid, instantaneous precipitation of the internal surface occurred, causing the accumulation of internal stress in the nascent fibre as the die swelling effect began to recede. As a result, the lumen was squeezed, causing the non-circularity. Similar morphology has also been seen elsewhere. ${ }^{20-22}$
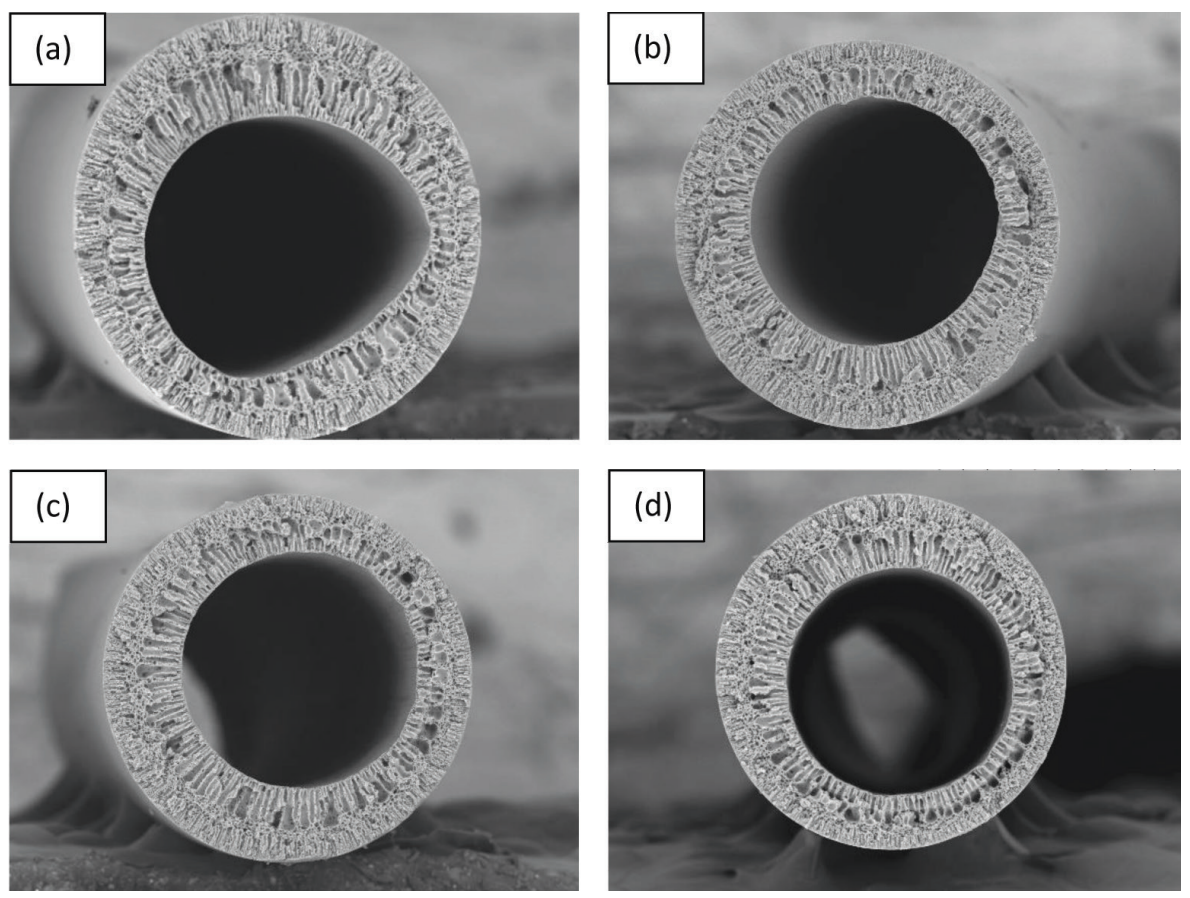

Figure 2: SEM cross sectional micrograph $(\times 150$ magnification $)$ of $\mathrm{HF}$ membrane samples spun at (a) $5 \mathrm{~cm}$, (b) $10 \mathrm{~cm}$, (c) $15 \mathrm{~cm}$, and (d) $20 \mathrm{~cm}$ respectively. 
Another distinct observation could be seen in Figure 2, in which the dimension of the fibres decreased with increasing air gap distance. The measured diameter of the hollow fibres are presented in Figure 3. The outer and inner diameter of HF sample spun at $20 \mathrm{~cm}$ (sample A.4) showed reduction of $17.82 \%$ and $17.73 \%$, from the initial $0.881 \mathrm{~mm}$ and $0.564 \mathrm{~mm}$ of sample A.1 respectively. This suggested a similar reduction in the fibre's diameter for both outer and inner dimensions. Note that for the non-circular lumen of sample A.1, the inner diameter is taken by calculating the perimeter of the non-circular lumen and assumed as the circumference of an equivalent circle. Considering that the formulation and all spinning parameters were the same except for air gap distances, it could be suggested that the linear reduction was due to gravitational stretching alone. T. S. Chung et al. have extensively studied the effect of air gap on the membrane dimension through mathematical derivation, which could be used to predict the final size of the fibers. ${ }^{8}$ The diameter was suggested to be affected by four parameters: (1) nascent hollow fiber density; (2) volumetric flow rate of bore fluid; (3) mass flow rate of dope solution; and (4) take-up rate of hollow fiber. While parameter (2), (3) and (4) was adjusted during the fiber spinning process, parameter (1) would depend on the formulation of the dope solution. As the spinning was done under the same formulation, gear pump flow rate and syringe pump flow rate, it could be concluded that the reduction of membrane's diameter was caused by different take-up speed needed to mitigate the gravitational stretching on the fibers. The modified formula is given by:

$$
\begin{aligned}
& D_{i}=2\left(V_{b} /\left(\pi v_{h}\right)\right)^{\frac{1}{2}} \\
& D_{o}=2\left(\left(V_{b}+V_{h}\right) /\left(\pi v_{h}\right)\right)^{\frac{1}{2}}
\end{aligned}
$$

where $D_{i}$ is the inner diameter, $D_{o}$ the outer diameter, $V_{b}$ the bore fluid volumetric flow rate, $V_{h}$ the dope solution volumetric flow rate, and $v_{h}$ the take-up speed of the hollow fiber. Table 2 presents the comparison between this experiment's diameter value with the calculated value, using the modified formula. Minor error of around $5 \%$ was noted in the inner diameter calculation while larger error of around $14 \%$ was noted for outer diameter calculation. This could be due to the modified formula noted for outer dimension, which assumes the density of the nascent hollow fiber to be equal to the density of dope solution. Hence, the term could be combined with mass flow rate of dope solution into the dope solution volumetric flow rate, $\mathrm{V}_{\mathrm{h}}$. In reality, the density would differ especially in solution with high solvent-polymer mixture ratio as phase separation removes the major constituent of solvent from the solution. Nevertheless, the error was acceptable, considering that similar error percentage was noted and thus should still provide a good approximation to the fiber's dimension. 
Table 2: Comparison of measured diameter with the calculated diameter. $D_{i}=$ inner diameter, $\mathrm{D}_{\mathrm{o}}=$ outer diameter, calc $=$ calculated value and $\exp =$ experimental value.

\begin{tabular}{ccccccccc}
\hline Sample & $\begin{array}{c}\mathrm{D}_{\mathrm{i}}, \text { calc } \\
(\mathrm{mm})\end{array}$ & $\begin{array}{c}\mathrm{D}_{\mathrm{i}}, \text { exp } \\
(\mathrm{mm})\end{array}$ & $\begin{array}{c}\text { Error } \\
(\mathrm{mm})\end{array}$ & $\begin{array}{c}\text { Error } \\
(\%)\end{array}$ & $\begin{array}{c}\mathrm{D}_{\mathrm{o}}, \text { calc } \\
(\mathrm{mm})\end{array}$ & $\begin{array}{c}\mathrm{D}_{\mathrm{o}}, \text { exp } \\
(\mathrm{mm})\end{array}$ & $\begin{array}{c}\text { Error } \\
(\mathrm{mm})\end{array}$ & $\begin{array}{c}\text { Error } \\
(\%)\end{array}$ \\
\hline A.1 & 0.591 & 0.564 & 0.027 & 4.493 & 1.015 & 0.881 & 0.134 & 13.235 \\
A.2 & 0.550 & 0.524 & 0.026 & 4.746 & 0.946 & 0.814 & 0.132 & 13.943 \\
A.3 & 0.517 & 0.494 & 0.023 & 4.446 & 0.889 & 0.765 & 0.124 & 13.942 \\
A.4 & 0.489 & 0.464 & 0.025 & 5.153 & 0.841 & 0.724 & 0.117 & 13.930 \\
\hline
\end{tabular}

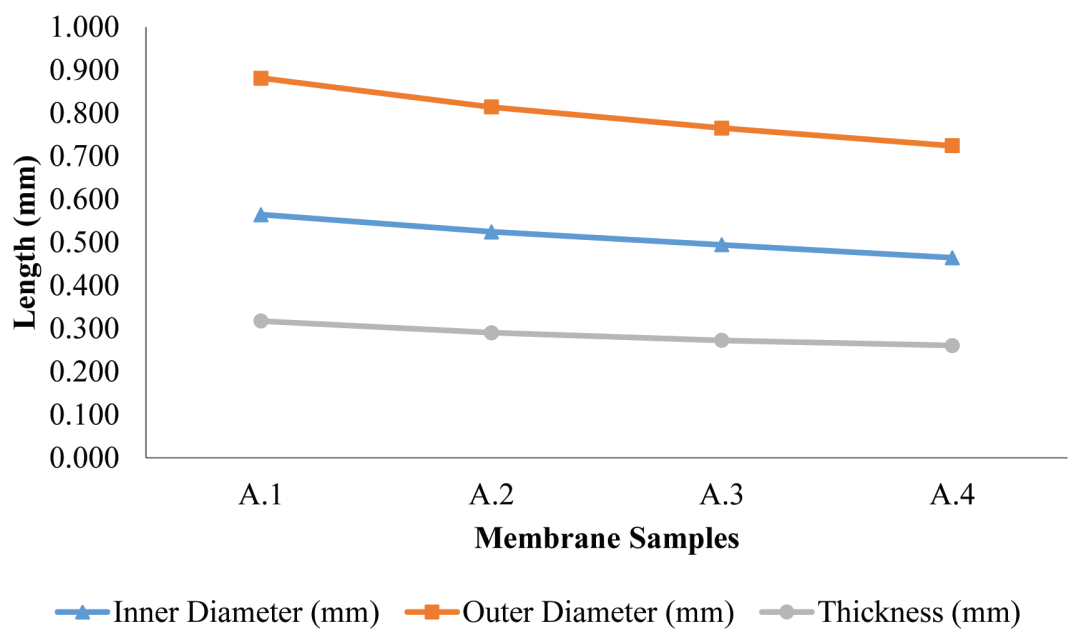

Figure 3: Effect of air gap on HF cross sectional diameters.

\subsection{Flux and Rejection Performance}

The results for the water flux (PWF) and humic acid flux (HAF) were presented in Figure 4 and Figure 5 respectively. Stable fluxes were noted on both graphs during the one hour permeation test. These suggested good antifouling properties as no significant reduction in flux was noted during the HAF study. The incorporation of hydrophilic PVA improve the hydrophilicity of the membrane samples and hence, making it less prone to fouling. ${ }^{14,23}$ Nevertheless, an antifouling test should be done in order to verify the claim, as noted in several antifouling studies..$^{24-26}$

On the other hand, flux were noted to increase with air gap distance for the PWF test, with sample A.1 at $5 \mathrm{~cm}$ air gap showed the lowest average PWF at $30.61 \pm 0.10 \mathrm{~kg} / \mathrm{m}^{2} . \mathrm{h}$, and an increment of $25.59 \%$ and $38.19 \%$ for the subsequent 
higher air gap distances for sample A.2 and A.3. Nevertheless, slight reduction was noted for sample A.4 with just 33.30\% improvement compared to sample A.1. Similar trends were noted for HAF test with sample A.1 showing the lowest average HAF at $31.31 \pm 0.14 \mathrm{~kg} / \mathrm{m}^{2} . \mathrm{h}$, followed by sample A.2 at $39.15 \pm 0.11$ $\mathrm{kg} / \mathrm{m}^{2} . \mathrm{h}$, and sample A.3 at $42.86 \pm 0.09 \mathrm{~kg} / \mathrm{m}^{2} . \mathrm{h}$. This was followed by slight reduction for sample A. 4 at $41.01 \pm 0.16 \mathrm{~kg} / \mathrm{m}^{2}$.h. The improvements were $25.05 \%$, $36.91 \%$, and $31.01 \%$ for samples A.2, A.3 and A.4, as compared to sample A.1 respectively. As discussed earlier on, there have been disputes on the effect of air gap on the HF membrane's permeation and rejection performance. Nevertheless, this work has followed the trend noticed in PES HF membrane work by Liu et al., in which the flux increased with air gap distance. ${ }^{5}$ Notwithstanding, the larger air gap distance induced in this study suggested that the higher air gap-higher flux

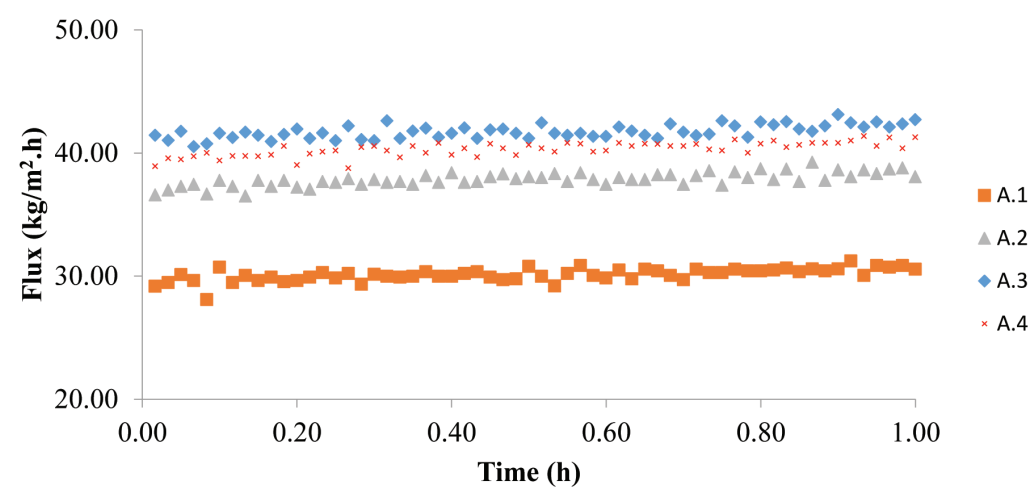

Figure 4: Pure water flux (PWF) performance with time. Flux taken every minute of permeation.

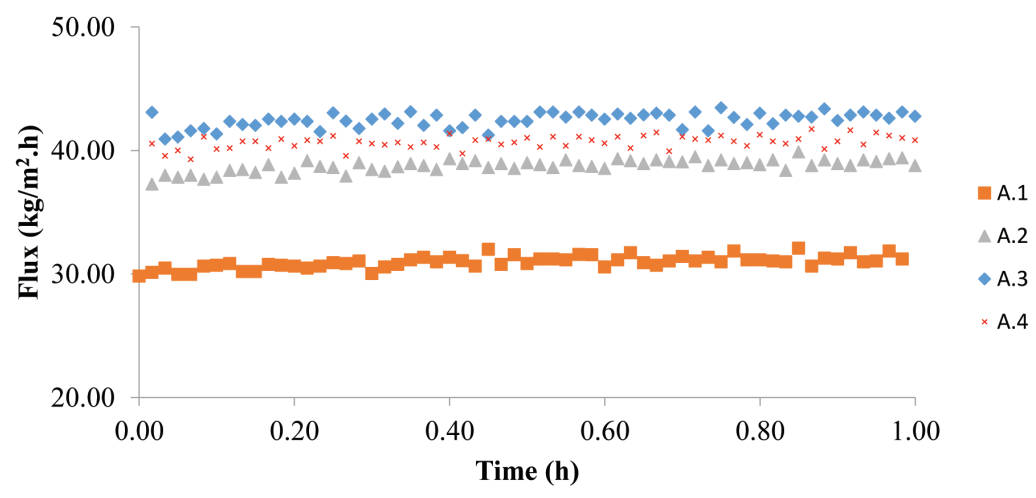

Figure 5: Humic acid flux (HAF) performance with time. Flux taken every minute of permeation. 
trend was only true up until a certain length, as noted in the reduction of sample A.4's flux. As the coagulated dope solution was passing the air gap region, the larger mass of the fibre at longer air gap could induce an increase of extrusion rate. Ismail et. al. have showed that at high extrusion rate, flux will decreased due to thicker and denser outer skin layer. ${ }^{27}$ Nevertheless, this claim did contradict with the previous claim on the effect of air gap. One hypothesis is that since air gap induced dope extrusion rate depends on the mass of coagulated dope solution in the air gap region, its effect will only be visible at high air gap distance, such as noted in sample A.4.

Moving on to the rejection performance, the rejection of humic acid (HA) by the membrane samples showed an inverse relationship with the HAF as sample A.1 gave the highest rejection at $94.63 \pm 2.13 \%$. As for sample A.2, A.3 and A.4, the rejections were declining by $1.48 \%, 8.88 \%$ and $2.39 \%$ respectively, showing an inverse relationship with the flux. The relationship was expected as the formulations of the membranes were the same, suggesting similar surface chemistry. Hence, the rejection trend was solely due to difference in pore size, which in turn increased the flux but decreased the rejection at bigger pore sizes. ${ }^{3-5,27}$

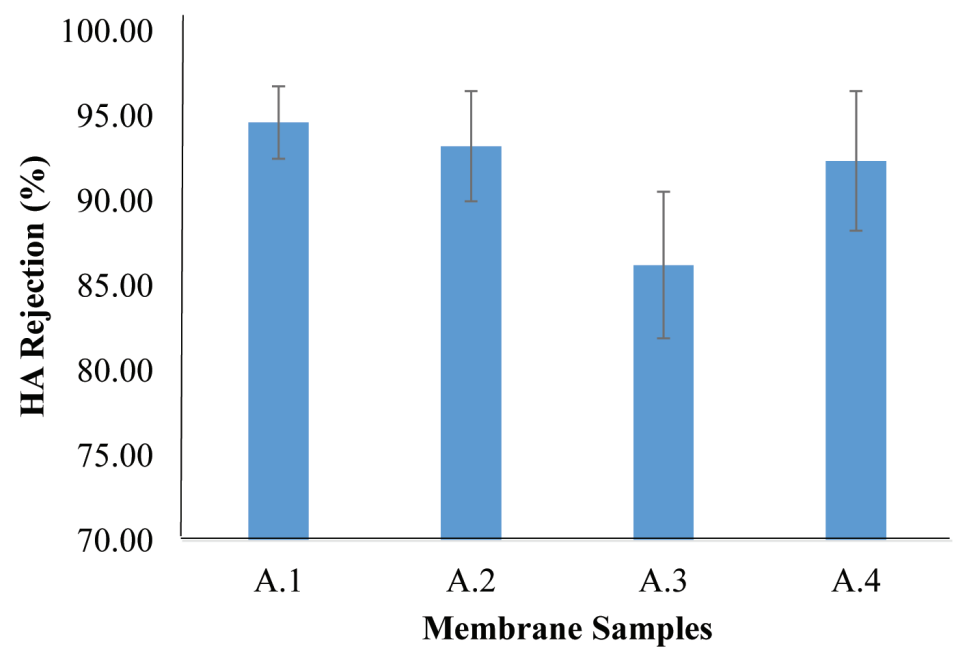

Figure 6: Effect of increasing air gap distance on HA rejection.

\subsection{Feasibility Studies}

By taking both flux and rejection as equally important (weightage at 0.5 for both), relative feasibility of the membranes was calculated. It was noted that despite the high rejection of sample A.1, it was not feasible for further studies at feasibility 
mark of only $86.52 \%$. The small flux could not compensate the small increment in rejection for the sample spun at $5 \mathrm{~cm}$ air gap distance. However, sample A.2, A. 3 and A. 4 showed almost similar feasibility at $94.93 \%, 95.56 \%$ and $96.65 \%$, respectively. Nevertheless, true feasibility could not be measured solely on the flux and rejection as a lot of factors contributed to the performance of the membranes. For example, the reduction in HF thickness as noted in Figure 3 suggested that longer air gap distance would reduce the mechanical strength of the membranes. Zhang et al. have reported on the effect of thickness on tensile strength and bursting pressure for PVDF HF membranes, in which both reduce with decreasing membrane thickness. ${ }^{28}$ As HF membranes were noted to be self-supporting, mechanical strength would be an important factor to determine the true feasibility.

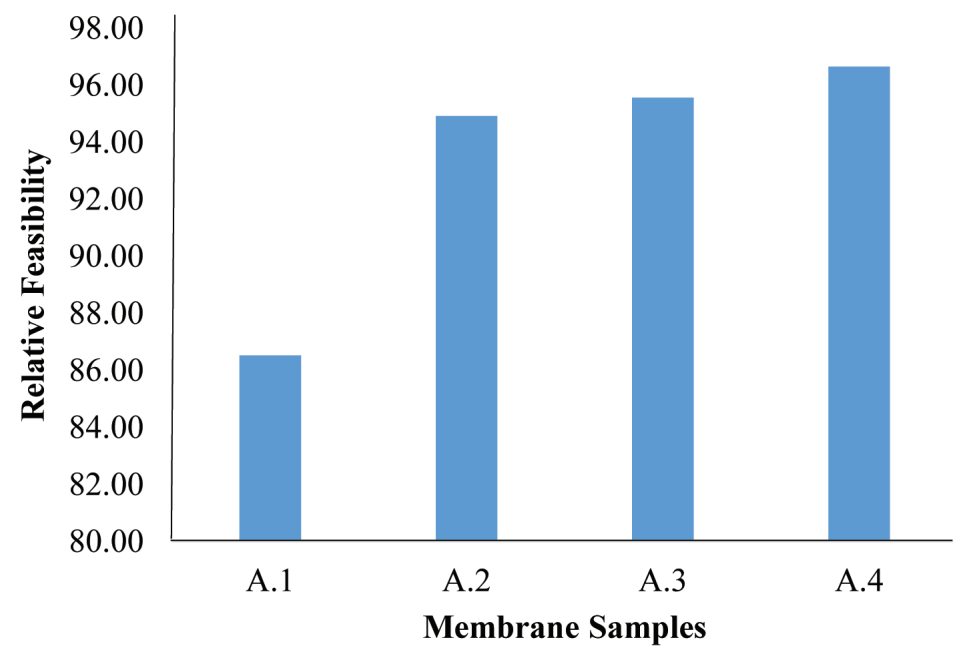

Figure 7: Membrane's feasibility by comparing HA flux and rejection at similar weightage.

\section{CONCLUSION}

The effect of air gap distance on the PES/PVA hollow fibre membrane morphology and performance was studied. Collinear pores could be seen in all membrane samples and minimum air gap distance of $10 \mathrm{~cm}$ was needed to fabricate hollow fibre membranes with circular inner lumen. Both the inner and outer diameter, as well as the thickness of the membranes were reduced with increasing air gap. The air gap distance could also alter the flux performance of the membranes with maximum HA flux at $42.86 \pm 0.09 \mathrm{~kg} / \mathrm{m}^{2}$.h with $15 \mathrm{~cm}$ air gap distance and maximum HA rejection at $94.63 \pm 2.13 \%$ with $5 \mathrm{~cm}$ air gap distance. 


\section{ACKNOWLEDGEMENTS}

Financial supports by Fundamental Research Grant Scheme (FRGS), Ministry of Higher Education Malaysia (Grant no: 203/PJKIMIA/6071334), the Long Term Research Grant Scheme (LRGS), Ministry of Higher Education Malaysia (Grant no: 203/PJKIMIA/6726101), and by Universiti Sains Malaysia RU Membrane Science and Technology Cluster (Grant no: 1001/PSF/8610011) are highly acknowledged.

\section{REFERENCES}

1. Moch Jr., I. (2004). Hollow fiber membranes. Encyclopedia of desalination and water resources (DESWARE). Paris: EOLSS Publishers.

2. Kirk-Othmer. (1998). Hollow fiber membranes. In Kirk-Othmer (Ed.). Encyclopedia of chemical technology Vol. 13. New York: John Wiley \& Sons.

3. Khayet, M. (2003). The effects of air gap length on the internal and external morphology of hollow fiber membranes. Chem. Eng. Sci., 58(14), 30913104, https://doi.org/10.1016/S0009-2509(03)00186-6.

4. Khayet, M., et al. (2009). Structural and performance studies of poly(vinyl chloride) hollow fiber membranes prepared at different air gap lengths. J. Membr. Sci., 330(1-2), 30-39, https://doi.org/10.1016/j.memsci.2008. 12.020 .

5. Liu, Y., Koops, G. H. \& Strathmann, H. (2003). Characterization of morphology controlled polyethersulfone hollow fiber membranes by the addition of polyethylene glycol to the dope and bore liquid solution. J. Membr. Sci., 223(1-2), 187-199, https://doi.org/10.1016/S0376-7388(03) 00322-3.

6. Chwojnowski, A. et al. (2009). Polysulphone and polyethersulphone hollow fiber membranes with developed inner surface as material for bio-medical applications. Biocyber. Biomed. Eng., 29(3), 47-59.

7. Peng, N., Chung, T.-S. \& Wang, K. Y. (2008). Macrovoid evolution and critical factors to form macrovoid-free hollow fiber membranes. J. Membr. Sci., 318(1-2), 363-372, https://doi.org/10.1016/j.memsci.2008.02.063.

8. Chung, T.-S., Xu, Z.-L. \& Lin, W. (1999). Fundamental understanding of the effect of air-gap distance on the fabrication of hollow fiber membranes. J.Appl. Polym. Sci., 72(3), 379-395, https://doi.org/10.1002/(SICI)10974628(19990418)72:3\%3C379::AID-APP8\%3E3.0.CO;2-B. 
9. Zhang, X. et al. (2008). Effect of air-gap distance on the formation and characterization of hollow polyacrylonitrile (PAN) nascent fibers. J. Macromol. Sci. B, 47(6), 1039-1049, https://doi.org/10.1080/0022234080 2266298.

10. Chetri, P., Dass, N. N. \& Sen Sarma, N. (2000). Development of a catalyst for solution of poly(vinyl alcohol) in non-aqueous medium. Chin. J. Polym. Sci., 2008. 26(4), 399-404, https://doi.org/10.1142/S0256767 908003060 .

11. Tosh, B., Saikia, C. N. \& Dass, N. N. (1999). Development of a nonaqueous solvent system for poly(vinyl alcohol) and its characterization. J. Appl. Polym. Sci., 74(3), 663-669, https://doi.org/10.1002/(SICI)1097-4628 (19991017)74:3\%3C663::AID-APP20\%3E3.0.CO;2-B.

12. Li, H.-B. et al. (2014). Effects of additives on the morphology and performance of PPTA/PVDF in situ blend UF membrane. Polym., 2014. 6(6), 1846-1861, https://doi.org/10.3390/polym6061846.

13. Yang, H. N. \& Kim, W. J. (2015). Effect of LiCl content on pore structure of catalyst layer and cell performance in high temperature polymer electrolyte membrane fuel cell. Energy, 90, 2038-2046, https://doi.org/10.1016/j. energy.2015.07.037.

14. Yuan, H. et al. (2014). Improved antifouling property of poly(ether sulfone) ultrafiltration membrane through blending with poly(vinyl alcohol). Ind. Eng. Chem. Res., 53(48), 18549-18557, https://doi.org/10.1021/ie502797k.

15. Zhang, J. et al. (2014). Modification of poly(vinylidene fluoride)/ polyethersulfone blend membrane with polyvinyl alcohol for improving antifouling ability. J. Membr. Sci., 466, 293-301, https://doi.org/10.1016/j. memsci.2014.05.006.

16. Hong, W. et al. (2011). Integral PVA-PES composite membranes by surface segregation method for pervaporation dehydration of ethanol. Chin. J. Chem. Eng., 19(5), 855-862, https://doi.org/10.1016/S1004-9541(11)60065-7.

17. Xu, Z.-L. \& Alsalhy Qusay, F. (2004). Polyethersulfone (PES) hollow fiber ultrafiltration membranes prepared by PES/non-solvent/NMP solution. J. Membr. Sci., 233(1-2), 101-111, https://doi.org/10.1016/j. memsci.2004.01.005.

18. Alsalhy, Q. F. et al. (2014). Poly(ether sulfone) (PES) hollow-fiber membranes prepared from various spinning parameters. Desalin., 345, 21-35, https://doi.org/10.1016/j.desal.2014.04.029.

19. Arahman, N. et al. (2012). Structure change of polyethersulfone hollow fiber membrane modified with pluronic F127, polyvinylpyrrolidone, and tetronic 1307. Mater. Sci. Appl., 3(2), 72-77, https://doi.org/10.4236/msa. 2012.32011. 
20. Pereira, C. C., Nobrega, R. \& Borges, C. P. (2000). Spinning process variables and polymer solution effects in the die-swell phenomenon during hollow fiber membranes formation. Brazil. J. Chem. Eng., 17, 599-606, https://doi.org/10.1590/S0104-66322000000400024.

21. Loh, C. H. \& Wang, R. (2014). Fabrication of PVDF hollow fiber membranes: Effects of low-concentration pluronic and spinning conditions. J. Membr. Sci., 466, 130-141, https://doi.org/10.1016/j.memsci.2014.04.021.

22. Shi, L. et al. (2007). Fabrication of poly(vinylidene fluoride-cohexafluropropylene) (PVDF-HFP) asymmetric microporous hollow fiber membranes. J. Membr. Sci., 305(1-2), 215-225, https://doi.org/10.1016/j. memsci.2007.08.012.

23. Guo, R. et al. (2008). Preparation and pervaporation performance of surface crosslinked PVA/PES composite membrane. J. Membr. Sci., 322(1), 32-38, https://doi.org/10.1016/j.memsci.2008.05.015.

24. Zhao, S. et al. (2015). Improving permeability and antifouling performance of polyethersulfone ultrafiltration membrane by incorporation of $\mathrm{ZnO}-\mathrm{DMF}$ dispersion containing nano-ZnO and polyvinylpyrrolidone. J. Membr. Sci., 478, 105-116, https://doi.org/10.1016/j.memsci.2014.12.050.

25. Liu, Y., Zhang, S. \& Wang, G. (2013). The preparation of antifouling ultrafiltration membrane by surface grafting zwitterionic polymer onto poly(arylene ether sulfone) containing hydroxyl groups membrane. Desalin., 316, 127-136, https://doi.org/10.1016/j.desal.2013.02.004.

26. Zhi, S.-H. et al. (2014). Poly(vinylidene fluoride) ultrafiltration membranes containing hybrid silica nanoparticles: Preparation, characterization and performance. Polym., 55(6), 1333-1340.

27. Ismail, A. F. et al. (2006). Effect of dope extrusion rate on morphology and performance of hollow fibers membrane for ultrafiltration. Sep. Purif. Technol., 49(1), 10-19, https://doi.org/10.1016/j.seppur.2005.08.001.

28. Zhang, Q., Lu, X. \& Zhao, L. (2014). Preparation of polyvinylidene fluoride (PVDF) hollow fiber hemodialysis membranes. Membr., 4(1), 81-95, https://doi.org/10.3390/membranes4010081. 
